\title{
A Dialética como Mito? Edmund Wilson e a recepção das "Ciências Vermelhas" britânicas em Nova York nos anos de 1930
}

Matheus Cardoso da Silva*

Resumo: Procuramos aqui investigar a crítica de Edmund Wilson às tentativas de ampliação das fronteiras do materialismo históricodialético para outros campos do conhecimento, em especial na "ciência vermelha" dos anos de 1930, criada como um projeto institucional na URSS, mas que tomou forma com os cientistas britânicos reunidos em torno da Social Relations in Science (SRS), a partir de 1931. No final daquela década, Wilson publicara nos EUA o texto "The Myth of Marxist Dialectic", onde exporá suas discordâncias quanto a estes projetos, baseadas principalmente naquilo que o crítico entendia ser a incapacidade dos marxistas em compreender as bases filosóficas do trabalho de Marx, entre elas, sua leitura da dialética hegeliana.

Palavras-chave: Edmund Wilson; ciência marxista; materialismo históricodialético.

Abstract: We seek to investigate the critic Edmund Wilson attempts to expand the boundaries of historical and dialectical materialism to other fields of knowledge, especially in "red science" of the 1930s, created an institutional project in the URSS, but it taken way in British scientists gathered around the Social Relations in Science (SRS), from 1931. At the end of that decade, Wilson published the text "The Myth of Marxist Dialectic," which will expose their disagreements on these projects, mainly based on what the critic understood to be the inability

* Historiador. Doutorando no Programa de Pós-Graduação em História Social, Departamento de História, Universidade de São Paulo. Bolsista da CAPES. E-mail: stardus_mat@yahoo.com.br 
of Marxists in understanding the philosophical underpinnings of Marx's work, including, his reading of the Hegelian dialectic.

Keywords: Edmund Wilson; Marxist science, historical and dialectical materialism.

\section{Introdução}

Em vez de libertar a mente do homem, a Revolução Bolchevique trancou-a na prisão de um estado mais forte do que nunca. No vôo de pensamento era concebível, não um passeio poético, não esgueirar-se através das portas ou o pio de uma janela neste calabouço pré-darwinista chamado Materialismo Dialético (Max Eastman, citado por Daniel Aaron, 1992, p. 124).

Em 1937, o biólogo inglês John Desmond Bernal publicaria na revista britânica Science \& Society o texto Dialetical Materialism and Modern Science, no qual defenderia a aplicação do materialismo dialético como método analítico das ciências naturais. Para Bernal, assim como para outros expoentes da "ciência vermelha", como ficou conhecido o projeto institucional em torno da fundação da Social Relations in Science (SRS), em Londres (1931), era justamente a dialética de Hegel aplicada como método de sistematização das relações humanas por Marx, que transformava o materialismo dialético em peça-chave para a superação de paradigmas epistêmicos que mantinham a pesquisa cientifica, em muitos sentidos, afastada daquele que deveria ser seu verdadeiro fim: a melhora da vida das pessoas em sociedade.

Do outro lado do Atlântico, Edmund Wilson, expoente crítico literário, jornalista e historiador da tradição marxista nos EUA, cuja obra fora fundamental para uma reflexão nativa sobre a teoria marxista, especialmente em Nova York, publicara um ano depois, nas páginas da revista nova-iorquina Partisan Review, o texto The Myth of Marxist Dialectic, que seria reproduzido (em formato ampliado) dois anos mais 
tarde em seu livro To the Finland Station (1940). Para Wilson, ao contrário de Bernal, a dialética (como ferramenta filosófica) representava uma barreira para a plena compreensão do significado do pensamento de Marx. A má interpretação do papel filosófico da dialética, assim como dos primórdios filosóficos do pensamento marxiano, produziam a redução do marxismo a uma teoria mecânica das relações econômicas no capitalismo.

Entre a visão positiva apresentada pelos "cientistas vermelhos" (dos quais Bernal era expoente) e a visão negativa de Wilson quanto ao papel da dialética no pensamento marxista estava posto um debate sobre as tentativas de alargamento das fronteiras do marxismo com o fim de transformá-lo em uma espécie de "teoria geral do conhecimento", encabeçada institucionalmente pelos soviéticos na III Internacional Comunista de 1919, e que se expandiriam para o universo cultural anglo-saxão em torno dos debates entre os círculos intelectuais de Londres e de Nova York, no final da década de 1940.

Nossa intenção em aproximar esses dois ambientes, especialmente ajustando o foco para os debates intelectuais dos dois lados do Atlântico, se dá pelo fato de, em nossa interpretação, representarem um momento importante de irradiação do "marxismo ocidental". Universo anglo-saxão que, contudo, foi "diminuído" nas análises de Perry Anderson, em seu já clássico estudo Considerações sobre o Marxismo Ocidental (1999) sobre a matéria, em detrimento de outros ambientes intelectuais, vistos por Anderson como importantes na produção original de uma releitura do marxismo fora da URSS. Como apresentaremos no debate a seguir, no entanto, as reflexões (e os debates gerados por elas) acerca da tentativa de renovação dos alcances do marxismo nos dois países, produziram sim, no mínimo, tensões entre a leitura oficial imposta pelo Partido Comunista da Grã-Bretanha e pelo Partido Comunista dos Estados Unidos, e as preposições de reinterpretação da teoria marxista (em especial, sobre seus alcances) entre esses intelectuais. 
O ponto deste artigo, contudo, não será propor um estudo da história das ciências. Essa só aparecerá aqui como ferramenta paralela para o estudo histórico do desenvolvimento de um problema intelectual, a saber: como as propostas de aplicação do marxismo no desenvolvimento de uma epistemologia científica compunham um projeto político-social de intelectuais da esquerda britânica, cujo papel foi importante também na divulgação do projeto comunista naquele país, e como se deu sua recepção nos EUA, no final da década de 1930. Como veremos, parte desse problema intelectual passava pelo debate sobre o papel da dialética no próprio marxismo anglo-saxão.

\section{Projetos para o alargamento das fronteiras do marxismo: a "ciência vermelha" e sua repercussão dos dois lados do Atlântico}

A aproximação da dialética marxista com o pensamento científico, numa tentativa de construção de uma epistemologia das ciências marxistas, fora pensada como parte fundamental do projeto oficial de Moscou, elaborado na III Internacional Comunista em 1919, para a transformação do marxismo numa teoria geral de análise das relações humanas (CERUTI, 1989; RAVETZ; WESTFALL, 1981).

As origens da fundação da "ciência vermelha" estão em uma conferência realizada em Londres em 1931. A conferência serviu para aglutinar todo o movimento internacional em gestação da "ciência vermelha" em torno do que ficou conhecido como Social Relations in Science, ou SRS. Inúmeras figuras-chave na cena acadêmica britânica assistiram a apresentação de uma série de trabalhos por N. Bukharin, em que expusera as relações do materialismo dialético para a iluminação das ciências naturais e sua relação com a sociedade. Iluminadoras foram as leituras que B. Hessen fez do Principia, de Newton, de um ponto de vista do materialismo histórico, e a crítica de V. Zaradovsky do debate vitalista/mecânico da biologia à luz do Dialética da Natureza (até então sem tradução do russo), de Engels. 
Além das proeminentes figuras de John Desmond Bernal e John Haldane, estavam ligados à SRS outros importantes nomes da cena científica britânica, como Hyman Levy, matemático e pioneiro da teoria aeronáutica; Joseph Needham, químico e embriologista e que se tornaria depois grande historiador da ciência chinesa antiga; e o biólogo social Lancelot Hogben, considerado um dos expoentes da área. Convertidos ao marxismo e crentes que a URSS era uma sociedade comprometida com a ciência, esses homens se dedicaram a partir daí a pensar o papel da ciência na sociedade britânica e explorar as possibilidades do materialismo histórico contribuir com a epistemologia científica.

O Marxismo se tornou então peça fundamental na história das ciências britânicas já que, agora definidas suas implicações sociais, seu papel no futuro coletivo precisava ser definido. Segundo Bernal, em seu The Social Function of Science, de 1939, todo o cientista comprometido da década de 1930 estava pressionado pelo empobrecimento forçado pelo capitalismo ou à perversão de seu trabalho nas mãos do fascismo, dos militares e imperialistas. Haldane, por sua vez, afirmara em 1946, que a Segunda Guerra Mundial havia começado para ele em 1936 e que desde então ele lutara contra a ideologia nazi e o militarismo japonês tanto quanto contra o imperialismo britânico e a exploração de Wall Street. Haldane não via problema, porém, em conciliar sua militância como "inglês" e "comunista", já que ele acreditava que a Inglaterra havia contribuído com o projeto de construção de uma ciência que planejava um futuro socialista (ROBERTS, 2005, p. 534-535).

Os debates em torno do alargamento das fronteiras conceituais do marxismo rumo à constituição de um método epistemológico, como o sugerido pela "ciência vermelha" na década de 1930, não era algo novo para a tradição marxista. Seus primórdios filosóficos já estavam delineados nos debates dos marxistas na década de 1920, em especial, nas controvérsias entre Lukács e Bukharin. O lançamento do História e Consciência de classe, de Georg Lukács, é emblemático. Lançado pela primeira vez em Berlim, em 1923, Lukács elabora uma espécie de 
síntese de sua obra até então, reunindo em duas partes uma série de artigos lançados na Hungria e na Alemanha, onde havia a formulação de alguns conceitos fundamentais: o conceito de "totalidade concreta", da "identidade sujeito-objeto na práxis social", do "conceito de consciência de classe" e de "reificação". Outro ponto fundamental na História e Consciência de Classe foi a recusa de Lukács da "dialética da natureza" de Engels, fundamental para a elaboração da "ciência marxista" soviética nos anos de 1940 (SOCHOR, 1987, p. 19).

Como conta a história, a versão oficial soviética prevaleceu. Os efeitos do dogmatismo "monista" da leitura soviética do marxismo, tão criticado por Lukács já na década de 1920, seriam a pedra angular do rompimento de muitos intelectuais com o movimento comunista internacional na década seguinte. Na metade dos anos de 1930, por exemplo, o movimento comunista dentro dos EUA se cinde, depois das controversas alterações nos rumos internacionais do movimento pela preposição das Frentes Populares como tática internacional de luta contra o fascismo, pelo VII Congresso da Internacional Comunista de 1935 e pelos efeitos da Guerra Civil Espanhola em 1936-1939.

O debate teórico em torno das projeções do pensamento marxista como método analítico em outros campos do conhecimento já estava posto nos EUA, no entanto, antes do racha causado na metade da década de 1930. E sua melhor confluência se deu através das paginas da revista The Modern Quarterly (mais tarde renomeada como Modern Monthly). Criada em Nova York, em 1923, a publicação durou até a morte de seu criador e editor-chefe, V. F. Calverton, em 1940. A revista representou um dos principais núcleos de debates teóricos sobre o marxismo daquela geração, aglutinando ao seu redor os principais teóricos do marxismo nos EUA até então - Sidney Hook, Max Eastman, Granville Hicks, Edmund Wilson etc. (BUHLE, 1992, p. 482-483) Para a revista, contribuiriam também nomes de expressão do pensamento marxista internacional, entre os quais os britânicos John Haldane e J. D. Bernal, expoentes do movimento SRS britânico. Em grande medida, os debates sobre a teoria marxista entre estes intelectuais em torno da The Modern Quarterly, estreitou as relações entre esses homens

\begin{tabular}{l|l}
\hline 60 & A Dialética como Mito? Edmund Wilson e a recepção das...
\end{tabular} 
e mulheres. E dali foi permitido à geração de jovens intelectuais radicais estadunidenses, recém-saídos da Era de Ouro pré-1929, ler e confrontar ideias produzidas pelos britânicos do outro lado do Atlântico.

Em 1938, Bernal encabeçaria a fundação da versão britânica da The Modern Quarterly, que foi rapidamente aceita pelo Communist Party of Great Britain (CPGB) pela oportunidade de ampliação dos debates em torno do marxismo. Ali se concentraria parte importante dos textos que os membros da SRS discutiriam as relações das ciências para com o marxismo. Claramente, o que estava em jogo nos debates travados na revista ao longo da década de 1940 era o papel desempenhado pelo movimento SRS como um contraponto intelectual ao fascismo e à crise econômica da década de 1930, enxergando na ciência uma saída para a reconstrução da sociedade ${ }^{1}$.

Haldane exploraria ainda em um livro, Advances of Science, publicado em Nova York, em 1948, a influência da URSS para o desenvolvimento de vários campos das ciências, como a climatologia, a geologia, a arqueologia, a hematologia e a genética, combinando a genética tradicional com o materialismo histórico. Haldane também seria enfático em sua crítica do racismo nazi, comparando-o as escolas britânicas e a história imperial de seu país. (ROBERTS, 1997, p. 535).

A adesão de Haldane ao marxismo se daria, contudo, ainda na década de 1930. Por volta de 1938, Haldane se torna um defensor do marxismo e de sua aplicação na epistemologia das ciências na interpretação das leis da natureza. Antes de sua adesão e de outros cientistas britânicos à "ciência vermelha", lembra Edwin Roberts, o grande expoente internacional entre os intelectuais da aproximação entre as ciências e o materialismo histórico fora o filósofo do Comintern, L. Rudas, cujo Dialectical Materialism and Communism (1935) fora

${ }^{1}$ Entre estes há uma série de artigos que Haldane publicou nas paginas da The Modern Quarterly: "Biology and Marxism". The Modern Quarterly, 3:4, outono, 2-11. 1948; "In Defense of Genetics". The Modern Quarterly, 4:3, verão, 194-202, 1949; "Marxism and History", The Modern Quarterly, 3:2, primavera, 52-64, 1948. 
largamente difundido na Grã-Bretanha pelo CPGB (ROBERTS, 1997, p. 535)

Após estar totalmente inteirado do Anti-Duhring, de Engels, e do Materialismo e Empiro-Criticismo, de Lenin, relembra autobiograficamente o próprio Haldane, já no final da década de 1940, ele adotaria o materialismo dialético como base para o entendimento do mundo natural. Roberts cita como exemplo o artigo inovador A dialectical Account of Evolution, de 1937, em que Haldane expõe muito mais sua já conhecida fórmula das contradições dos mecanismos de evolução, através de seu darwinismo/mendelianismo, do que uma exposição sistemática sobre o materialismo dialético. Sua visão sobre a dialética era ainda desarticulada, baseada numa leitura "anglófona" da tríade Hegeliana, de "tese-antítese-síntese", e também não distinguindo claramente se a dialética era para ele ontológica ou lógica (ROBERTS, 2005, p. 535-536).

Internamente, as reflexões em torno da aplicação da dialética marxista na epistemologia científica passaram, inevitavelmente, por um debate filosófico entre os "cientistas vermelhos" e seus críticos do CPGB. O aprofundamento teórico nos campos da filosofia dos cientistas extrapolavam as barreiras da ortodoxia do partido. Uma vez mais, Edwin Roberts lembra o caso de Heyman Levy que tentara provar, através das "leis da probabilidade a veracidade das leis da dialética de transformação da quantidade em qualidade e a união dos opostos (também continuando as reflexões de Lenin sobre a teoria do conhecimento". A crítica do lado do CPGB veio através de Clements Dutt, primeiro tradutor do Dialética da Natureza de Engels na Grã-Bretanha, e a acusação de que a leitura da dialética praticada por Levy ignorava o corpo da teoria do materialismo dialético produzido fora da Grã-Bretanha e, ainda, de que Levy forçava a dose, tentando modificar o significado do conceito de dialética para agradar o público britânico (ROBERTS, 2005, p. 536)².

2 Bertrand Russel, outra figura proeminente entre os cientistas e os comunistas britânicos, também entrou no debate que se seguia entre Dutt e os membros da SRS.

\begin{tabular}{l|l}
\hline 62 & A Dialética como Mito? Edmund Wilson e a recepção das...
\end{tabular} 
Dentro do movimento da SRS, no entanto, uma visão positiva do papel da dialética permanecia. J. D. Bernal, se alinharia a Haldane quanto a defesa das aplicações da dialética nas ciências duras, argumentando que ela, a dialética, auxiliaria as ciências a entender "não coisas, mas processos", além de oferecer às ciências uma visão de seu background histórico. Bernal, contudo, seria mais contundente em suas reflexões sobre a aplicação do materialismo dialético na epistemologia científica, antecipando um debate crítico sobre o tema ainda no final da década de 1920. Mesmo antes da formação da SRS, Bernal antecipou em muitas medidas seus temas-chave em seu livro, The World, The Flesh, and the Devil, de 1929 (ROBERTS, 2005, p. 538). Por isso, Bernal já estava devidamente convencido das possibilidades da aplicação do marxismo na epistemologia científica quando da apresentação dos soviéticos no Congresso da História das Ciências e da Tecnologia, em Londres, em 1931. Sobre aquele momento, encantado com o "projeto soviético", Bernal escreveria, em 1949: "A história da ciência era de tão vital importância para eles; não era apenas enquanto estudo acadêmico, mas como um guia de ação." "Para Bernal”, completa Roberts, "ciência era história e história era política"3:

Russell, que já havia demonstrado simpatia para com as preposições da SRS, publica em 1938 o artigo Philosophy and Common Sense na revista conservadora britânica, The New Statesman and Nation. Neste texto, Russell critica duramente o materialismo dialético como uma teoria metafísica e um sistema irracional, criticando os cientistas que aderiam à leitura da SRS sobre as ciências como dogmáticos e filosoficamente simplistas. O artigo de Russel exibe um tipo de crítica da dialética que me parece bem parecido, como veremos a seguir neste artigo, com a crítica que Edmund Wilson apresentará quase que simultaneamente nos EUA. O tema central, a saber: a dialética como um circuito fechado (ao invés de universalista, ou, adaptável aos diferentes métodos de pesquisa) que, ao contrário do que propalavam os projetos da "ciência vermelha", reduzia ainda mais as capacidades do marxismo como uma filosofia metafísica.

${ }^{3}$ John Desmond Bernal, "The Biological Controversy in the Soviet Union and its Implications", The Modern Quarterly, 14:3, summer, 203-17, 1949. Citado por Roberts, 2005, p. 358. 
A partir daqui ele viu que a ciência e a tecnologia devem ser integradas na forma de desenvolvimento industrial planejado. Ele rejeitou o trabalho científico com base em desejos ou necessidades individuais, em favor da ciência como uma atividade social, democraticamente organizado e desenvolvido. (ROBERTS, 2005, p. 538. Citado a partir do artigo de Bernal, "Science and Man", Left Review, 2, novembro, 1935, p. 69-74)

Tal projeto porém fora visto em alguns círculos mais afastados de intelectuais, como no contexto dos EUA, como uma tentativa de ampliação dos alcances do pensamento marxiano para muito além do que havia pensado Marx, mesmo em suas reflexões sobre as ciências humanas ou naturais (como n'A Ideologia Alemã, na Introdução a crítica da economia política e n'O Capital). Mesmo Engels, que se ocupou mais detidamente no final do século XIX sobre a aproximação do marxismo e as ciências duras, por exemplo, no Anti-Duhring, ainda tinha reservas quanto às funções do materialismo dialético na elaboração de uma ciência que retratasse a luta de classes como algo orgânico, intrínseco às relações humanas.

Essa crítica emerge nos círculos intelectuais dos EUA ainda na década de 1920 e ocupa toda a década de 1930, especialmente nas reflexões de nomes como Max Eastman, Sidney Hook e o próprio Edmund Wilson. Em todos estes autores, frutificaram tentativas originais de construção de uma leitura nativa do pensamento marxiano ou, no mínimo, de uma adaptação do marxismo às condições históricas dos EUA (BUHLE, 1997, p. 30).

Max Eastman, por exemplo, que junto com Wilson, Hook, Granville Hicks e John Reed, entre outros, compuseram a primeira geração de intelectuais que transformaram a cidade de Nova York no epicentro do radicalismo filosófico-literário daquela geração, viajaria à Rússia em 1922, permanecendo nove meses pesquisando no Instituto Marx e Engels de Moscou. Sua passagem por entre os arquivos do Instituto que publicara pela primeira vez muitos dos

\begin{tabular}{l|l}
\hline 64 & A Dialética como Mito? Edmund Wilson e a recepção das...
\end{tabular} 
textos de Marx ainda inéditos até então, credenciou-o como um dos primeiros tradutores da obra de Marx do russo para o inglês nos EUA e depois da obra de Trotsky. No período em que passou em Moscou, Eastman passou a estudar seriamente as obras de Marx e Lenin, e dali elaboraria, mais tarde, sua conclusão da corrupção do Stalinismo e seu dogmatismo na interpretação do marxismo. Essa crítica ficaria bem clara em um panfleto que Eastman lança em Londres, em 1938, intitulado The End of Socialism in Russia, publicado pela editora Martin Secker and Warbourg. Ainda ao longo da década de 1930, Eastman produziria também textos fundamentais para a reflexão da relação entre o marxismo, a filosofia (em especial, ao pragmatismo de John Dewey, cuja relação seria aprofundada por seu colega Sidney Hook) e as ciências. Um exemplo dessas aproximações é o artigo, "Marxism: Science or philosophy?", publicado na revista nova-iorquina de orientação trotskysta New International, em agosto de $1935^{4}$.

Em grande parte, as críticas do papel do materialismo dialético elaboradas por Eastman influenciariam todo o círculo intelectuais ao seu redor - com especial reflexo em Hook e em Wilson. O próprio Wilson viajara para a Rússia em 1935, como parte do projeto de pesquisa para o seu livro To the Finland Station, que seria publicado e por fim em $1940^{5}$.

${ }^{4}$ Como é possível apreender na leitura do To the Finland Station, de Wilson, ambos, Max Eastman e Sidney Hook, desempenhariam papel fundamental entre os intelectuais marxistas dos EUA que emergiriam dos círculos boêmios de Nova York, não apenas como comentadores e tradutores de Marx e Engels, mas por suas tentativas originais em refletir a relação entre o marxismo, a filosofia pragmática e as ciências. Comentando as tentativas de Engels de continuar as reflexões de Marx após sua morte sobre a dialética, primeiro no Anti-Duhring, e depois ao longo de suas cartas, Wilson rememora também as tentativas de conexão das reflexões de ambos por Eastman em, Marx, Lenin and the science of revolution (1927), e Hook em, Towards the Understanding of Karl Marx (1933). (WILSON, 1986:176)

${ }^{5}$ As memórias de suas viagens, inclusive para a Rússia stalinista, foram narradas no livro Red, Black, Blond and Olive: studies in Four Civilizations, uma copilação que Wilson lança em 1956. 
Apesar de ter sua obra reconhecida muito mais como crítico literárioejornalista, Wilsonflertou coma teoria marxista, sem, noentanto, ter produzido substancialmente nesse campo. Suas contribuições para a renovação do marxismo entre o que se convencionou chamar de "Intelectuais de Nova York" foram fundamentais, mesmo assim, especialmente por seus esforços de aplicação do marxismo no campo da teoria e da crítica literária. Trabalhos como seu Axel's Castle (1931) seriam fundamentais na releitura da tradição modernista nos EUA, se não ainda sob uma perspectiva explicitamente marxista, ao menos como o preâmbulo de uma crítica à sociedade industrial dos EUA e à sua tradição. Crítica que influenciara definitivamente, por exemplo, o círculo de intelectuais em torno da revista nova-iorquina Partisan Review (do qual Wilson era dileto integrante) depois de sua separação do PC nos EUA, em $1937^{6}$. Ainda, a posição de Wilson enquanto um dos símbolos intelectuais daquela geração ajudou a consolidar entre as novas gerações as posições independentes de crítica ao dogmatismo comunista nos EUA. Com isso, ele foi capaz de estabelecer uma ponte entre os círculos privados da intelligentsia marxista boêmia de Nova York que ascende no cenário público estadunidense nos anos de 1920 e um público mais amplo, compondo o modelo ideal do "intelectual público" nos EUA (SAMUELS, 1996, p. 20).

Ao longo da segunda metade da década de 1930, Wilson produzirá uma série de trabalhos em que se oporá ao projeto institucional soviético de ampliação das fronteiras do marxismo e sua transformação em uma teoria geral do conhecimento. Essa crítica culminara com o lançamento do seu To The Finland Station, em 1940, em que Wilson afirma categoricamente que "a dialética [era] um

\footnotetext{
${ }^{6}$ E a Partisan Review, após romper com o PC em 1937, devido discordâncias com a tática Frentista adotada pelo VII Congresso da Internacional Comunista, de 1935, se consolida na história intelectual dos EUA, a partir de 1938 e ao longo da década de 1940, como o principal círculo intelectual da esquerda anti-stalinista naquele país. Wilson contribuiria diretamente nessa "nova fase" da revista, publicando intensamente entre o final da década de 1930 e ao longo da década seguinte, participando efetivamente na consolidação das ideias anti-stalinistas do editorial da Partisan naquele período.
}

\begin{tabular}{l|l}
\hline 66 & A Dialética como Mito? Edmund Wilson e a recepção das...
\end{tabular} 
mito religioso". E entre esses "maus usos" do pensamento marxista criticados por Wilson, estava, justamente, sua crítica à "ciência vermelha" britânica.

\section{O "mito da dialética" ou a recepção das "ciências vermelhas" por Edmund Wilson}

Antes da publicação do To the Finland Station, Wilson já havia publicado outros trabalhos, entre artigos e livros, nos quais colocava em xeque a ortodoxia da leitura oficial soviética do marxismo, adotada pelos PC ao redor do mundo, inclusive em sua seção estadunidense. Entre estes, por exemplo, Travels in Two Democracies (1936), no qual o autor "expressava sua crítica à burocracia soviética ao mesmo tempo que não hesitou em criticar os comunistas dos EUA de maneira mais direta" (WALD, 1986, p. 157). Outro foi The Triple Thinkers (1938), onde denunciava o stalinismo como uma perversão do marxismo e não sua continuidade. Por fim, no To the Finland Station, Wilson queria relembrar a importância da Revolução de Outubro para o pensamento marxista.

Na primavera de 1938, Wilson publicaria na revista Partisan Review, o artigo The Myth of Marxist Dialetic. Esse mesmo texto, ampliado, seria incluído dois anos mais tarde no livro To the Finland Station ${ }^{7}$. Os anos de pesquisa sobre a teoria e a história do pensamento marxista para o livro marcariam a transição que a relação de Wilson com a teoria marxista sofreu. Neste texto Wilson partirá da tentativa de recuperação da ideia original da dialética de Hegel e da interpretação de sua utilização no materialismo dialético por Marx (WILSON, 1986, p. 173-174). Wilson começa, a partir daí, a diferenciar o pensamento de Marx (inclusive sua aplicação na história da dialética hegeliana)

\footnotetext{
7 Wilson, E. "O Mito da Dialética". Rumo a Estação Finlândia: escritores e atores da história. São Paulo, Companhia das Letras, 1986. pp.173-191. Nossa referência aqui será essa versão estendida incluída como capítulo no livro de Wilson e traduzido para o português do artigo publicado originalmente na Partisan Review, em 1938.
} 
da leitura da tradição marxista desse pensamento que, incapaz de entender o distanciamento filosófico de Marx para com Hegel, tornou o marxismo uma mera reprodução mecânica das formas (ou "fases") da dialética hegeliana.

$\mathrm{Na}$ abertura do ensaio, Wilson se propõe a analisar as diferenças entre a dialética para Platão e para Hegel: "A dialética utilizada por Platão era uma técnica de chegar à verdade através da conciliação de duas afirmativas opostas." Já para Hegel, segundo a leitura de Wilson,

[a dialética] era uma lei que também envolvia contradição e conciliação, só que para Hegel, ela atuava não apenas no domínio da lógica, mas também no mundo natural e da história. O mundo está sempre mudando, diz Hegel; porém, há nessas transformações um elemento de uniformidade: o fato de que cada processo de mudança atravessa necessariamente um ciclo de três fases" (WILSON, 1986, p. 173)

Definidas as linhas centrais da dialética para Hegel, cabia então desmontá-la para compreendê-la. Wilson passa então a investigar cada fase da dialética de Hegel:

A primeira delas, que Hegel denomina tese, é um processo de afirmação e unificação; a segunda, a antítese, é um processo de dissociação e negação da tese; a terceira é uma nova unificação, que concilia a antítese com a tese e é denominado síntese. Estes ciclos não são simples recorrências, que deixem o mundo tal como era antes: a síntese é sempre um avanço em relação à tese, pois ela combina, numa unificação mais "elevada", o que há de melhor na tese e na antítese. Assim, para Hegel, a unificação representada pelo inicio da República Romana constituiu uma tese. Essa unificação inicial fora realizada por grandes patriotas como os Cipiões, porém com o passar do tempo o patriota 
republicano assume um caráter diverso: a "individualidade colossal" da era de César e Pompeu, uma individualidade que tende a perturbar o Estado à medida que a ordem republicana começa a se deteriorar sob a influência da propriedade romana - esta é a antítese que se dissocia da tese. Porém por fim, Júlio César derrota seus rivais, as outras individualidades colossais e impões à civilização romana uma nova ordem, autocrática, uma síntese, que promove uma unificação maior: o Império Romano. (WILSON, 1986, p. 173-174)

Para Wilson, fora esta a fórmula empregada por Marx e Engels em sua tipificação do materialismo dialético, transformando a dialética em uma ferramenta para a análise do futuro, coisa que não estava em Hegel:

Marx e Engels adotaram esse princípio, e projetaram sua atuação no futuro, coisa que Hegel não havia feito. Para eles, a tese era que a sociedade burguesa, que constituía uma unificação em relação ao regime feudal que se desintegrava: a antítese era o proletariado, que fora gerado pelo desenvolvimento da industria moderna, mas que depois fora dissociado, através da especialização e do aviltamento do corpo principal da sociedade moderna, e que um dia teria que se voltar contra ela; a síntese seria a sociedade comunista que resultaria do conflito entre a classe operária e as classes patronais e do controle da indústria pela classe operária, e que representaria uma unidade mais elevada na medida em que harmonizaria os interesses de toda a humanidade (WILSON, 1986, p. 174).

Salientando a oposição de Marx e Engels ao idealismo filosófico, Wilson partirá para criticar a tradição e a intelligentsia marxista, devido a sua leitura rarefeita e oblíqua do próprio marxismo e das 
relações humanas na sociedade capitalista, a qual cabe ao marxismo investigar. "Marx e Engels haviam rejeitado o que eles denominavam de 'mecanicismo puro' dos filósofos franceses do século XVIII", lembra Wilson. "Assim, na sociedade - para citar mais uma carta de Engels não é verdade que a situação econômica seja a única causa atuante e tudo o mais não passe de um efeito passivo" (WILSON, 1986, p. 175).

O que interessava a Wilson neste texto específico, mas que compõe o projeto geral de seu livro, era recuperar em Engels e em Marx suas reflexões para além das bases econômicas da sociedade - das relações entre a base, formada pelos meios de produção e a superestrutura da sociedade e seus troncos - "o direito, a filosofia, a religião e a arte" (WILSON, 1986, p. 177). O autor citará como exemplo disso um trecho de Marx em um manuscrito da Introdução à crítica da economia política, quando Marx vai pensar a relação entre a arte e a sociedade na Grécia antiga:

Num rascunho de Introdução à crítica da economia política, Marx havia tentado explorar as dificuldades de se estabelecerem [relações] entre arte e condições econômicas. Observa ele que os períodos de maior desenvolvimento artístico não coincidem com os de maior progresso na sociedade. Grandes obras de artecomo as epopeias gregas, por exemplo - não são necessariamente produtos de um período de elevado desenvolvimento social. Em relação a qualquer caso especifico, é possível entender por que uma forma específica de arte floresceu num momento específico: a própria ingenuidade dos gregos, que não haviam ainda inventado a imprensa, sua proximidade à mitologia primitiva numa época em que ainda não fora inventado o para-raios, quando ainda era possível imaginar que um relâmpago era sinal 
da ira de Zeus, o encanto infantil de uma sociedade ainda em sua infância - tudo isso fez com que a arte dos gregos antigos se tornasse, "sob certos aspectos, um padrão e modelo inatingíveis". O difícil era descobrir as leis gerais que determinam a relação entre desenvolvimento artístico e desenvolvimento social (WILSON, 1986, p. 177-178) ${ }^{8}$.

O outro ponto fundamental na crítica de Wilson à tradição marxista e sua tentativa de transformação do pensamento marxiano numa "teoria universal" (o que, por fim, iria esvaziá-la) era sua relação com as ciências. $\mathrm{O}$ autor, neste sentido, ressaltará outro problema em Marx e Engels: enquanto "tinham que acreditar" na validade de seu trabalho como um trabalho científico, ou seja, que terá algum impacto sobre a sociedade, tinham, ao mesmo tempo, que reconhecer que ele também era ideologia, estando, assim também, na superestrutura (WILSON, 1986, p. 178). Neste sentido, Wilson recordará um trecho do prefácio de Marx do Crítica da Economia política, na qual afirma que:

[...] deve-se sempre fazer uma distinção entre a transformação material das condições econômicas de produção, que pode ser determinada com a precisão da ciência natural, e as formas legais, políticas, religiosas, estéticas ou filosóficas - em suma, ideológicas - por meio das quais os homens se conscientizam desse conflito e nele se engajam" (Marx, Crítica da Economia política, citado por Wilson, 1986, p. 178).

Para o autor, analisando esse trecho retirado de Marx, “[...] a ciência natural não se inclui entre as formações ideológicas da superestrutura, porém possui uma precisão que as outras não podem

\footnotetext{
${ }^{8}$ Wilson lembraria ainda que Marx tocou na questão das relações entre desenvolvimento artístico e desenvolvimento social, assim como o fez nas Teses sobre Feuerbach, porém, sem nunca chegar a uma conclusão.
} 
ter; e essa precisão está ao alcance da ciência social" (WILSON, 1986, p. 179).

Wilson apontará que essa afirmação - que legitima e dá força às ciências (humanas e naturais) em detrimento aquelas áreas afetadas pela ideologia por pertencerem à superestrutura, como a arte - seria, no entanto, desmentida por ambos em trabalhos posteriores: na Ideologia Alemã, quando Marx e Engels escrevem que "até mesmo as ciências naturais 'puras' inicialmente derivam seus objetivos, bem como materiais, do comércio e da indústria, das atividades perceptíveis dos seres humanos"; e em O Capital, quando Marx escreve o mesmo sobre os perigos dos interesses individuais (capitalistas) com que as ciências se defrontam (WILSON, 1987, p. 179). Engels também, no Anti-Duhring, vai afirmar a complexidade na percepção das relações entre as formas de evolução econômicas e políticas das sociedades e o pensamento humano, através da lógica e da dialética. Wilson, com isso, tentará demonstrar um processo de evolução nas ideias de Marx e Engels através de pequenas contradições internas expostas em importantes trabalhos como os citados acima.

Mais do que humanizar seus autores e as origens do pensamento marxista em suas raízes, Wilson provocava seus contemporâneos, em meios aos debates da esquerda estadunidense de finais dos anos de 1930 e início de $1940^{\circ}$. A exposição dessas contradições internas nas obras

\footnotetext{
${ }^{9}$ Nos EUA, em especial em Nova York, as disputas internas do movimento comunista seriam fundamentais na história de muitos intelectuais e das revistas que os empregavam, muitas delas, financiadas pelo PC. O momento mais emblemático da cisão na esquerda intelectual de Nova York é o caso já citado neste artigo da Partisan Review. Em 1937, pouco antes de romper definitivamente com o PC, se inicia um importante e longo debate editorial entre a Partisan e o New Masses - revista comunista que agregava grande parte da primeira geração de intelectuais comunistas de NY sobre o papel da arte na promoção da revolução socialista. Enquanto a New Masses defendia a primazia dos debates em torno de questões políticas e econômicas como fundamentais para a superação das contradições da sociedade capitalista nos EUA, a Partisan defendia que as questões culturais poderiam sim cumprir papel fundamental na promoção das ideias socialistas através da superação dos valores estéticos e culturais burgueses (COONEY, 1986).
} 
de Marx e Engels, desse vai-e-vem de ideias, explora a complexidade em se propor uma crítica estética da arte e da literatura baseada no pensamento marxista, tanto quanto ignorá-la completamente, em detrimento de seu fechamento no universo da ideologia e da superestrutura. E isso se aplica também, segundo Wilson, na visão da possibilidade de um equilíbrio das forças sociais e políticas dentro do Estado, por classes antagônicas. O que contraria a premissa básica de que o Estado é um instrumento de dominação da burguesia sobre o proletariado ${ }^{10}$.

De volta à interpretação do papel das ciências para o pensamento marxiano, Wilson fará referência aos estudos de Marx no final de sua vida sobre a matemática e aos estudos de Engels, sobre matemática, física, química e zoologia, "na tentativa de provar que o processo dialético regia o mundo natural" (WILSON, 1986, p. 184). E neste ponto, Wilson retomaria os debates incitados pela "ciência vermelha" britânica, na preposição de uma ciência baseada no materialismo dialético. No entanto, sob uma perspectiva muito mais pessimista de suas possibilidades de alcance do que, como vimos acima, John Desmond Bernal e a SRS o fezeram.

O uso da dialética na tentativa de uma interpretação da ciência por Engels era, na visão de Wilson, uma clara mostra das dificuldades de sua aplicação em todos os campos do conhecimento humano:

Não foi difícil criticar Engels - que utilizou alguns exemplos tirados diretamente da Lógica de Hegel - mostrando que ele estava distorcendo os fatos ao argumentar que a "negação da negação" (ou seja, a atuação da antítese sobre a tese) podia ser demonstrada matematicamente, verificando-se que a negação da negação de a era $+\mathrm{a}^{2}$, “a grandeza positiva inicial, porém em um

\footnotetext{
${ }^{10}$ Wilson apontará essa contradição através do 18 Brumário de Louis Bonaparte, de Marx, e no A origem da Família de Engels, ambos analisando a situação histórica da sociedade francesa (WILSON, 1986, p. 179).
} 
nível mais elevado". A negação de - a, obviamente, não é $\mathrm{a}^{2}$ e sim a; e para obter-se $a^{2}$ sequer é preciso negar: basta multiplicar +a por $+a$. É bem verdade que Engels reconhece a necessidade de construir desse modo a primeira negação para que a segunda "permaneça ou se torne possível". Mas como, nesse caso, o materialista dialético é sempre obrigado a impor suas próprias condições para chegar a resultados dialéticos, como sustentar que a dialética é inerente a todos os processos da natureza? (WILSON, 1986, p. 184-185) $)^{11}$.

Nesse ponto, Wilson citará Sidney Hook e seu artigo Dialectic and Nature, publicado na revista Marxist Quarterly ${ }^{12}$, em 1937. Como Hook argumentará neste texto, o exemplo citado por Engels acima detinha, em sua argumentação, o exato problema dos exemplos retirados das experiências de Bernal e Haldane na Inglaterra. Como escreve Wilson, relembrando as argumentações de Hook, "as descobertas citadas por Bernal foram feitas sem que se utilizasse o raciocínio dialético", assim como “[...] a elaboração da tabela periódica de Mendelev, que tanto impressionou Engels como exemplo da qualidade determinada pela quantidade nada teve a ver com antítese e síntese [...]" (WILSON, 1986, p. 185).

O projeto de aplicação da dialética na epistemologia científica em pesquisas financiadas por Moscou com o intuito de validar a leitura soviética do marxismo como "teoria científica geral", e que seria a base, como vimos, de fundação da SRS britânica é, com efeito, apresentada por Wilson com ironia:

\footnotetext{
11 E Marx, para Wilson, analisava da mesma maneira: O mesmo se dá com a "transição da quantidade para a qualidade", um princípio hegeliano cuja atuação Marx julgava encontrar tanto na transformação do chefe da guilda medieval em capitalista quanto nas transformações dos compostos da série do carbono através do acréscimo de moléculas (id., ibid.).

12 Sidney Hook. "Dialectic and Nature," Marxist Quarterly, April-June 1937, p. 255-283.
} 
No caso de mais uma teoria de Bernal - a teoria freudiana da repressão dos desejos - o ciclo dialético, sem dúvida alguma, nada tem de inevitável. O instinto é a tese; a repressão é a antítese; a sublimação é a síntese: até ai, tudo bem. Mas digamos que o paciente não consiga sublimar e enlouqueça, ou se suicide: onde está a conciliação dos opostos na síntese? Onde está a progressão do mais baixo para o mais elevado? Sem dúvida é verdade que em diversos campos ocorrem mudanças através de acumulações que nos dão a impressão de serem qualificados. É possível que, como afirma J. B. S Haldane, a transformação do gelo em água ainda seja um fenômeno misterioso. Mas de que modo isso prova a existência da Trindade dialética? E de que modo a prova do professor Haldane, ao apresentar os processos de mutação e seleção sob a forma de tríades? Ou Hegel, ao dispor toda a sua argumentação em três partes? Ou Vico, quando insiste em ver tudo em trincas: três tipos de idiomas, três sistemas de direito, três formas de governo etc? Ou Dante, quando divide seu poema em três seções com trinta e três cantos cada uma? (WILSON, 1986, p. 186).

Wilson conclui que, diante da incapacidade de aplicação geral da dialética em todos os campos do pensamento humano, e sua falha de aplicação nas ciências duras, que ela, a dialética, se transformava nesses projetos (como o da SRS britânica) em uma redoma filosófica impenetrável, em meio a leitura oficial do marxismo soviético, tornando-o (o marxismo) quase que uma doutrina divina, que só podia ser acessado pelos iniciados em seu culto oficial. $O$ resultado disso: a dialética, por fim, tomava as formas de "um mito religioso":

Assim, a dialética é um mito religioso, dissociado da personalidade divina e vinculado à história da humanidade. 
"Odeio todos os deuses", Marx dissera quando jovem; porém ao mesmo tempo ele se projetara na personagem do marinheiro decidido que traz no peito a autoridade dos deuses, e um de seus primeiros artigos sobre liberdade de imprensa publicados no Rheinische Zeitung, ele afirma que o escritor deve, “a seu modo, adotar os princípios do pregador religiosos, adotar o principio 'obedecer a Deus e não ao homem', em relação àqueles seres humanos entre os quais ele se vê confinado por seus desejos e necessidades humanas" (WILSON, 1986, p. 187).

Wilson foi muito claro em apontar que para ele a dialética serviria como uma espécie de círculo hermético, inclusive ideológico, no qual o processo de interação das relações humanas em sociedade é reduzida ao jogo eterno ("idealístico", contrariando seu princípio fundamental de negação da filosofia idealista da leitura de Marx e Engels de Hegel) do jogo de forças dos opostos:

A dialética simplifica desse modo as coisas: parece reduzir as complexidades da sociedade à conviç̧ão de que a luta não apenas será vitoriosa, mas também dará fim a todos os conflitos dessa ordem, para sempre. Assim, a verdadeira validade da tríade dialética é servir de símbolo da eterna insurreição das forças da vida jovem e em crescimentos contra tudo que é velho e estéril, dos instintos cooperativos da sociedade contra o que é bárbaro e anárquico. Representa um progresso em relação ao ponto de vista por ela substituído - "Abaixo o tirano! Queremos liberdade!" na medida em que concebe o processo revolucionário como um desenvolvimento orgânico com base no passado, o qual vem sendo preparado, de certa forma, pelas próprias forças da reação, 
e que combina em si os diferentes recursos das duas partes em conflito ao invés de limitar-se a substituir uma coisa por outra (WILSON, 1986, p. 188).

\section{Conclusão}

Wilson será enfático ao afirmar não apenas a necessidade em se compreender a "temporalidade" da crítica de Marx como teoria crítica da sociedade da Europa no século XIX. Será um dos primeiros críticos a reconhecer, nos EUA, as limitações no pensamento de Marx, e apontar lacunas importantes em sua teoria. Para Wilson, a crítica dialética da sociedade capitalista exposta em Marx, não conseguiu (por razões históricas) alcançar pontos importantes da sociedade. Com isso, o autor nunca pretendeu, no entanto, subestimar ou, menos ainda, refutar Marx e a importância de sua obra. Sua crítica, na verdade, era dirigida à esquerda que apropriara seu pensamento como "testamento", ou como um "mito religioso", desconectando-o de sua função primordial de compreender as desigualdades da sociedade, sobre a qual a rememoração das premissas básicas da teoria marxista ajudaria a recuperar (COONEY, 1986, p. 175).

Nos EUA, o projeto da SRS fora visto por críticos como Wilson como uma tentativa mal-fadada de "alargamento de fronteiras" do marxismo, baseada principalmente numa interpretação rígida do materialismo dialético. Essa leitura "mecânica" do papel da dialética no pensamento marxiano e sua aplicação nas ciências naturais (mas também humanas) produzia, segundo Wilson, os mesmos problemas que reduziam (ao contrário de ampliar) o marxismo a uma teoria "economicista", que transformava todas as esferas da sociedade em subproduto das superestruturas. Conclusão precipitada que ignorava o fato de outros campos das relações humanas, como a arte, a literatura e a crítica estética, atuarem como ideologia, sendo possível através delas a promoção das ideias socialistas e do marxismo como uma teoria sociológica de análise da sociedade. 
Em muitos sentidos, essa dualidade de visões acerca do papel da dialética, apresentada na critica de Wilson ao projeto da SRS britânica, criaria uma importante rede de comunicação entre os dois universos intelectuais - o britânico e o estadunidense - em torno dos debates teóricos sobre o marxismo. Mesmo que os círculos novaiorquinos (em especial nesse caso) não tivessem algum integrante diretamente envolvido com o grupo da SRS, a quantidade de reflexões teóricas que o debate gerou ali, transformou sua visão (contrária aos auspícios dos "cientistas vermelhos"), num importante contraponto a esse projeto e produziu importantes reflexões teóricas acerca das possibilidades de aplicação do marxismo como uma teoria social ampla, para além das limitações impostas pelo dogmatismo dos PC's em ambos os países.

Entre a visão negativa de Wilson sobre o papel da dialética no pensamento marxista e, por exemplo, a visão positiva de J. D. Bernal, estava delineado um sério debate sobre as extensões do marxismo como teoria crítica. Cada uma dessas visões expressava, contudo, uma clara certeza: de que o marxismo tinha mais a dizer à sociedade do que a ortodoxia stalinista permitia-lhe. De um lado ou de outro do Atlântico, o que estava em jogo, de fato, era a liberdade de reflexão dos intelectuais marxistas em sua busca pelos reais alcances teóricos do pensamento de Marx e Engels na práxis social daquela geração.

\section{Referências Bibliográficas}

AARON, Daniel. Writers on The Left. Episodes in American literary communism. New York: Columbia University Press, 1992.

ANDERSON, Perry. Considerações sobre o Marxismo Ocidental. São Paulo: Brasiliense, 1999.

BERNAL, John D. "Dialectical Materialism and Modern Science". Science \& Society, vol. 2, no. 1, Winter, 1937b, p. 58-66. Disponível em: https://www.jstor.org/stable/40399130. 
BERNAL, John D. "Engels and Science." Labour Monthly Pamphlets. n. 6. S-d, 2008. The Trinity Trust. London. Marxist Internet Archive, Disponível em: http://www.marxists.org/archive/ bernal/works/1930s/engels.htm.

BERNAL, John D. "Psycho analisys and Marxism". The Labour Monthly. vol. 19. n. 7. Julho, 1937a. p. 435-437. Marxist Internet Archive. Disponível em: http://www.marxists.org/archive/bernal/ works/1930s/psycho.htm

BUHLE, Paul. Marxism in the United States. London: Verso, 1997.

BUHLE, Paul. BUHLE, Mary. GEORGAKAS, Dan. Enclyclopedia of American Left. Chicago: University of Illinois Press, 1992.

CERUTI, Mauro. “O materialismo dialético e as ciências nos anos 30". In. HOBSBAWM, Eric. (org). História do Marxismo. São Paulo: Paz e Terra. 1989. Volume 9. p. 315-86.

COONEY, Terry. The Rise of the New York intellectuals. Partisan Review and its circle, 1934-1945. Winscosin: The University of Winsconsin Press, 1986.

ENGELS, Friedrich. Dialética da Natureza. São Paulo: Paz e Terra, 1985.

EASTMAN, Max. "Marxism: Science or Philosophy?" New International, August 1935, p. 159-163. Disponível em: http://www.marxists. org/archive/eastman/1935/science-philosophy.htm.

EASTMAN, Max. The End of Socialism in Russia. London: Martin Secker and Warbourg, 1938. Disponível em: http://www.marxists.org/ archive/eastman/1938/end-socialism.htm. 
GOULD, Stephen Jay. "A Darwinian Gentleman at Marx's Funeral". Natural History. 108.7, Sept. 1999, p. 32. Disponível em: http://go.galegroup.com/ps/i.do?\&id=GALE $\mid$ A55698600\&v=2. $1 \& \mathrm{u}=$ capes $58 \& \mathrm{it}=\mathrm{r} \& \mathrm{p}=\mathrm{AONE} \& \mathrm{sw}=\mathrm{w}$.

HALDANE, John B.S. "Preface". In. ENGELS, F. Dialectics of Nature. 1939. Disponível em: http://www.marxists.org/archive/marx/ works/1883/don/preface.htm.

RAVETZ, Jerome. WESTFALL, Richard S. "Marxism and the History of Science". Isis, vol. 72, no. 3, Sep, 1981, p. 393-405. Disponível em: https://www.jstor.org/stable/230257.

ROBERTS, Edwin. "From the History of Science to the Science of History: Scientists and Historians in the Shaping of British Marxist Theory." Science and Society, vol. 69. n. 4. Outubro, 2005. p. 529-558.

ROBERTS, Edwin. The Anglo-Marxists. Studies in Ideology and Culture. Rowman and Littlefield, Boston, 1997.

SAMUELS, David. "Edmund Wilson and the Public Intellectuals". The Wilson Quarterly (1976-) vol. 20, no. 1 (Winter, 1996), p. 102-112. Disponível em: http://www.jstor.org/stable/40259305.

STURDY, Steve. "Biology as Social Theory: John Scott Haldane and Physiological Regulation". The British Journal for the History of Science, vol. 21, no. 3 (Sep., 1988), pp. 315-340 Disponível em: https://www.jstor.org/stable/4026832

TOIBIN, Colm. "Edmund Wilson: American Critic." The New York Times, september, 4, 2005. Disponível em: http://www.nytimes. com/2005/09/04/books/review/04TOIBIN.html?pagewanted=all 
WALD, Alan M. The New York Intellectuals: The rise and decline of the Anti-stalinist left from the 1930s to the 1980s. Chapell Hill: The University of North Carolina Press, 1987.

WILSON, Edmund. Anos vinte: extraídos dos cadernos e diários. São Paulo: Companhia das Letras, 1987.

WILSON, Edmund. O castelo de Axel: estudo acerca da literatura imaginativa de 1870-1930. São Paulo: Cultrix, 1967.

WILSON, Edmund. Rumo à Estação Finlândia: escritores e atores da história. São Paulo: Companhia das Letras, 1986.

WILSON, Edmund. "O Mito da Dialética". In: Rumo a Estação Finlândia: escritores e atores da história, São Paulo: Companhia das Letras, 1986. p. 173-91. 
